\title{
ANALISA KESTABILAN GERAKAN STATIS PADA ROBOT HUMANOID
}

\author{
Nicko Satrio Pambudi ${ }^{1}$, Dewa Made Wiharta ${ }^{2}$, Nyoman Putra Sastra ${ }^{3}$ \\ Jurusan Teknik Elektro, Fakultas Teknik Universitas Udayana \\ Email: satrio.nicko@gmail.com ${ }^{1}$, wiharta@unud.ac.id ${ }^{2}$, putra.sastra@unud.ac.id ${ }^{\underline{3}}$
}

\begin{abstract}
Abstrak
Tujuan dari penelitian ini adalah untuk merancang bangun robot humanoid yang dapat berjalan dengan stabil dan tidak mudah jatuh. Robot humanoid ini dirancang agar dapat mengikuti ajang perlombaan Kontes Robotika Indonesia kategori robot humanoid sepak bola yang diselenggarakan oleh Kemenristekdikti. Robot dapat berjalan dengan stabil pada lapangan berumput dan mampu menggiring bola lalu memasukannya ke gawang lawan. Robot yang digunakan menggunakan 8 servo dynamixel $A X-12$ dan 10 servo dynamixel $A X-18$. Robot dilengkapi dengan sebuah kamera pada bagian kepala robot dengan rangka akrilik. Untuk mendeteksi kemiringan robot digunakan sensor MPU6050. Kontrol utama yang digunakan adalah Raspberry Pi. Robot dikatakan stabil jika selama melakukan pergerakan robot tidak mudah terjatuh. Untuk mencapai kestabilan pergerakan robot secara statis perlu diperhatikan titik COG (Center of Gravity) dari robot agar selalu tegak lurus dengan support polygon atau tumpuan robot.. Hasil dari pengujian sensor MPU6050 menunjukkan ketika robot miring ke depan atau ke belakang maka output sumbu $Y$ mengalami perubahan dan ketika miring ke kiri atau ke kanan maka output sumbu $X$ akan berubah. Pengujian gerakan statis robot menunjukan bahwa robot berhasil tidak terjatuh selama berjalan.
\end{abstract}

Kata Kunci : Center of Gravity, Raspberry, Sensor MPU6050, Servo Dynamixel

\section{PENDAHULUAN}

Perkembangan teknologi semakin berkembang terutama dibidang sistem kendali. Salah satu dari perkembangan tersebut adalah pada bidang robotika. Berbagai macam jenis robot telah dibuat dan dikembangkan demi memenuhi keperluan manusia. Mulai dari robot yang dapat membantu pekerjaan rumah, robot yang digunakan pada industri, maupun robot yang digunakan untuk hiburan. [1]

Di Indonesia terdapat kompetensi robot yang diadakan oleh pemerintah untuk tingkat perguruan tinggi yakni "Kontes Robot Indonesia" (KRI). Kontes ini memiliki 5 cabang kategori perlombaan, salah satunya adalah "Kontes Robot Sepak Bola Indonesia" (KRSBI) humanoid. KRSBI yang sudah terselenggara sejak tahun 2013. Kegiatan ini dinilai pemerintah sangat strategis untuk dapat menjadi salah satu obyek penelitian Di Universitas Udayana, terdapat Unit Kegiatan Mahasiswa (UKM) yang dan edukasi rekayasa robotika tingkat dunia dengan kiblat langsung kepada komunitas yang sama di seluruh dunia. Kontes ini juga menjadi ajang kualifikasi nasional untuk mewakili Indonesia dalam RoboCup yang merupakan kompetisi robot sepak bola resmi tingkat dunia di bawah organisasi RoboCup, seperti organisasi FIFA dalam kejuaraan dunia sepak bola manusia. [2]

Pada kompetisi KRSBI ini, robot diharapkan secara autonomous (tanpa dikendalikan oleh user) dapat mendeteksi bola serta dapat menggiring bola ke gawang lawan. Tentu tidak mudah dalam membangun sistem pada robot agar sesuai dengan harapan yang ingin dicapai. Salah satu sistem yang dibangun adalah pada pergerakan robot yang memerlukan perhitungan matematika yang cukup kompleks agar pergerakan robot stabil dan tidak mudah jatuh. mempelajari tentang robotika dan teknologi telah memiliki robot humanoid dan telah 
diikutsertakan pada KRI cabang kategori "Kontes Robot Seni Tari Indonesia" (KRSTI). Pada kompetisi ini, robot masih belum memiliki stabilitas pada pergerakan robot.

Dalam mengatasi kestabilan pergerakan robot secara statis perlu diperhatikan titik COG (Center of Gravity) dari robot humanoid dalam setiap pergerakannya agar selalu berada pada support polygon. Dalam penelitian ini akan dilakukan analisa terhadap pergerakan robot secara statis dengan menerapkan teori COG (Center of Gravity).

\section{BAHAN DAN METODE}

\subsection{Robot Bioloid GP}

Robot Bioloid GP merupakan Robot Humanoid yang diproduksi secara massal oleh perusahaan robotis. Robot Bioloid GP diperuntukan sebagai robot yang dapat mengikuti kompetisi dengan memiliki struktur tubuh yang terbuat dari aluminium serta aktuator yang terdiri dari servo dynamixel $A X$ 18A dan AX-12A. Robot Bioloid GP memiliki pusat pengendali yakni CM-530. Robot Bioloid GP juga memiliki 2 sensor yang dapat digunakan yakni sensor gyro dan sensor infrared. Robotis telah menyediakan program Graphical User Interface (GUI) untuk memudahkan pengguna dalam memprogram serta merekam gerakan pada Robot Bioloid GP. Program tersebut adalah Roboplus Task, Roboplus Motion, dan Roboplus Manager. Roboplus Task berfungsi untuk memprogram Robot Bioloid GP dengan menggunakan bahasa pemograman $C$. Pengguna dapat memberikan instruksi pada robot melalui Roboplus Task. Roboplus Motion berfungsi untuk membangkitkan pose gerakan pada Robot Bioloid GP. Roboplus Manager berfungsi untuk memonitoring hardware pada Robot Bioloid GP yang dapat memberikan informasi hardware pada pengguna.

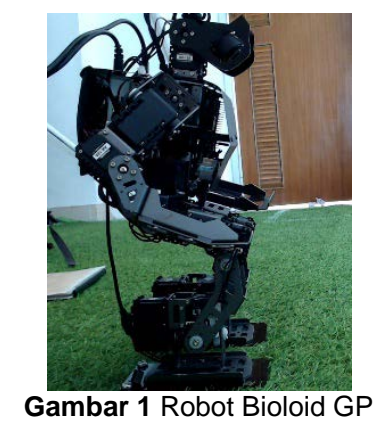

\subsection{Servo Dynamixel}

Motor servo adalah sebuah motor servo dengan sistem closed feedback dimana posisi dari motor servo akan diinformasikan kembali ke rangkaian kontrol yang ada dalam motor servo [3]. Motor servo terdiri atas dua jenis yakni servo digital dan servo analog. Perbedaan kedua jenis servo terletak pada sinyal dan bagaimana sinyal itu diproses dari penerima ke servo dan bagaimana servo menggunakan informasi dari penerima untuk menggerakkan servo sesuai dengan sudut yang diinginkan. Motor servo dynamixel yang digunakan pada Robot Bioloid GP menggunakan tipe AX-18A dan AX-12A. Perbedaan dari kedua tipe tersebut terletak pada torsi. Tipe AX-18A memiliki torsi yang lebih besar daripada tipe AX-12A.

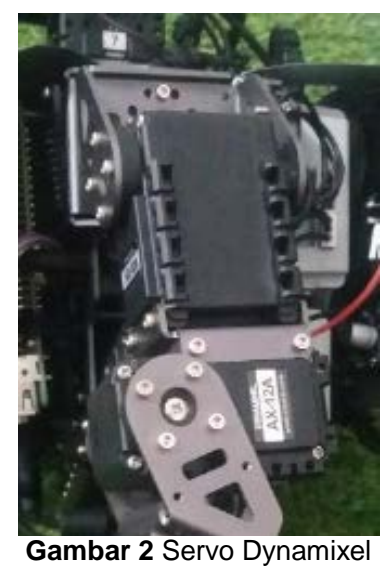

Servo dynamixel bekerja dengan menerima instruksi paket data dari main controller yang kemudian data yang diterima diolah untuk menggerakkan servo atau meminta data sensor yang ada pada servo dynamixel. Instruksi data yang dikirimkan oleh main controller menggunakan komunikasi serial half duplex, oleh karena usb serial pada main controller menggunakan 
komunikasi serial full duplex maka diperlukan suatu converter yang dapat mengubah komukasi serial full duplex menjadi half duplex.

\section{$2.3 \quad \mathrm{U} 2 \mathrm{D} 2$}

U2D2 merupakan modul yang berfungsi sebagai alat komunikasi untuk mengirim perintah yang berupa paket instruksi kepada actuator dynamixel. Agar dapat berkomunikasi dengan servo dynamixel diperlukan komunikasi data Half duplex dan U2D2 merupakan alat yang mengubah komunikasi data Full Duplex menjadi Half Duplex.

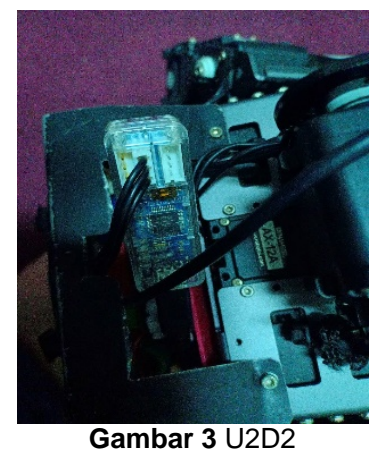

Tabel 1 Port U2D2

\begin{tabular}{|c|c|}
\hline \multicolumn{1}{c|}{ Tabel 1 Port U2D2 } \\
\hline Port & Deskripsi \\
\hline 4 Pin UART & Mengubah USB dan UART \\
\hline 3 Pin TTL & $\begin{array}{c}\text { Dynamixel Port dengan 3 pin } \\
\text { Komunikasi TTL }\end{array}$ \\
\hline 4 Pin TTL & $\begin{array}{c}\text { Dynamixel Port dengan 4 pin } \\
\text { Komunikasi RS-485 }\end{array}$ \\
\hline Status LED & $\begin{array}{c}\text { Menampilkan status dari Power } \\
\text { Supply, TxD dan RxD }\end{array}$ \\
\hline Micro-B USB & $\begin{array}{c}\text { Menyambungkan ke PC melalui kabel } \\
\text { USB }\end{array}$ \\
\hline
\end{tabular}

\subsection{Raspberry Pi}

Raspberry Pi (RasPi) merupakan komputer berukuran kecil yang ukurannya hampir sama dengan sebuah kartu yang dikembangkan oleh Yayasan Raspberry $\mathrm{Pi}$ yang bermarkas di Negara Inggris. Dalam Raspberry $\mathrm{Pi}$ ini sudah dilengkapi dengan prosesor ARM1176JZF-S $700 \mathrm{MHz}$, RAM sebesar $256 \mathrm{MB}$ dan juga sebuah GPU
VideoCore IV. Dan untuk penyimpanan data, Raspberry Pi tidak menggunakan Hard Disk namun Raspberry Pi dapat menggunakan SD Card untuk menyimpan data, baik itu data Operating System ataupun untuk media penyimpanan data jangka panjang. Raspberry Pi sudah banyak digunakan dalam berbagai kegiatan akademis yang berkaitan dengan teknologi maupun robotika. Penggunaan Raspberry Pi pada tugas akhir ini adalah sebagai main controller pada robot humanoid yang memberikan data kepada sub controller.

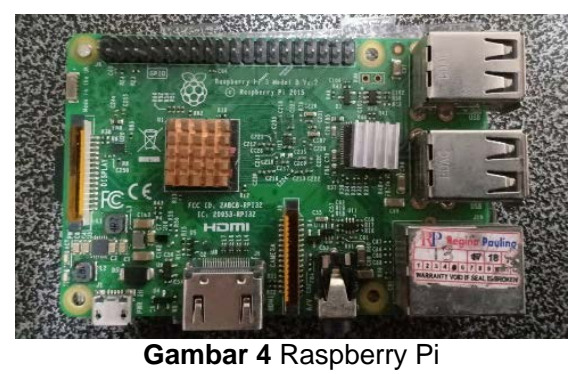

\subsection{Sensor MPU6050}

Sensor MPU6050 merupakan sensor yang terdiri atas sensor accelerometer dan sensor gyro yang berada pada satu papan. Sensor MPU6050 digunakan sebagai pendeteksi perubahan kemiringan robot bioloid GP berdasarkan perubahan pada roll, pitch, dan yaw.

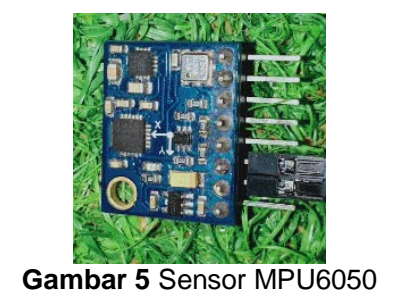

\subsection{Center of Gravity (COG)}

Center of Gravity atau pusat gravitasi merupakan sebuah titik dimana massa benda terdistribusi secara merata. Titik ini selalu berubah-ubah apabila suatu objek mengalami perubahan bentuk. Pada robot humanoid titik ini selalu berubah seiring dengan perubahan gerakan pada robot. Robot humanoid dikatakan dalam keadaan seimbang apabila titik Center of Gravity dari robot berada pada area tumpuan robot [4]. Robot humanoid memiliki 2 fase tumpuan yakni, SSP (Single 
Support Phase) dan DSP (Double Support Phase). Robot humanoid berada pada fase SSP jika robot humanoid mengangkat satu kaki dan bertumpu pada satu kaki saja sedangkan pada fase DSP merupakan suatu keadaan robot humanoid pada saat bertumpu pada dua kaki.

\subsection{Desain Sistem}

Pada tugas akhir ini robot humanoid yang digunakan adalah robot Bioloid GP yang telah diubah pada bagian kepala robot dengan menggunakan satu servo AX-12 Dynamixel sehingga bagian kepala robot dapat bergerak secara vertical dan sebuah kamera yang dipasang pada servo tersebut dengan menggunakan frame yang terbuat dari bahan akrilik seperti pada gambar 6 .

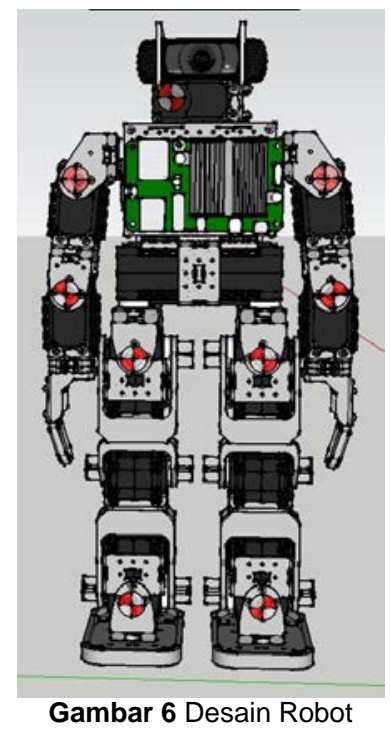

Pada sistem kontrolnya, Raspberry Pi 3 Model B akan digunakan sebagai pengontrol utama (main controller) dan U2D2 digunakan sebagai sub-pengontrol (sub controller). Desain elektronik robot dapat digambarkan pada gambar 7.

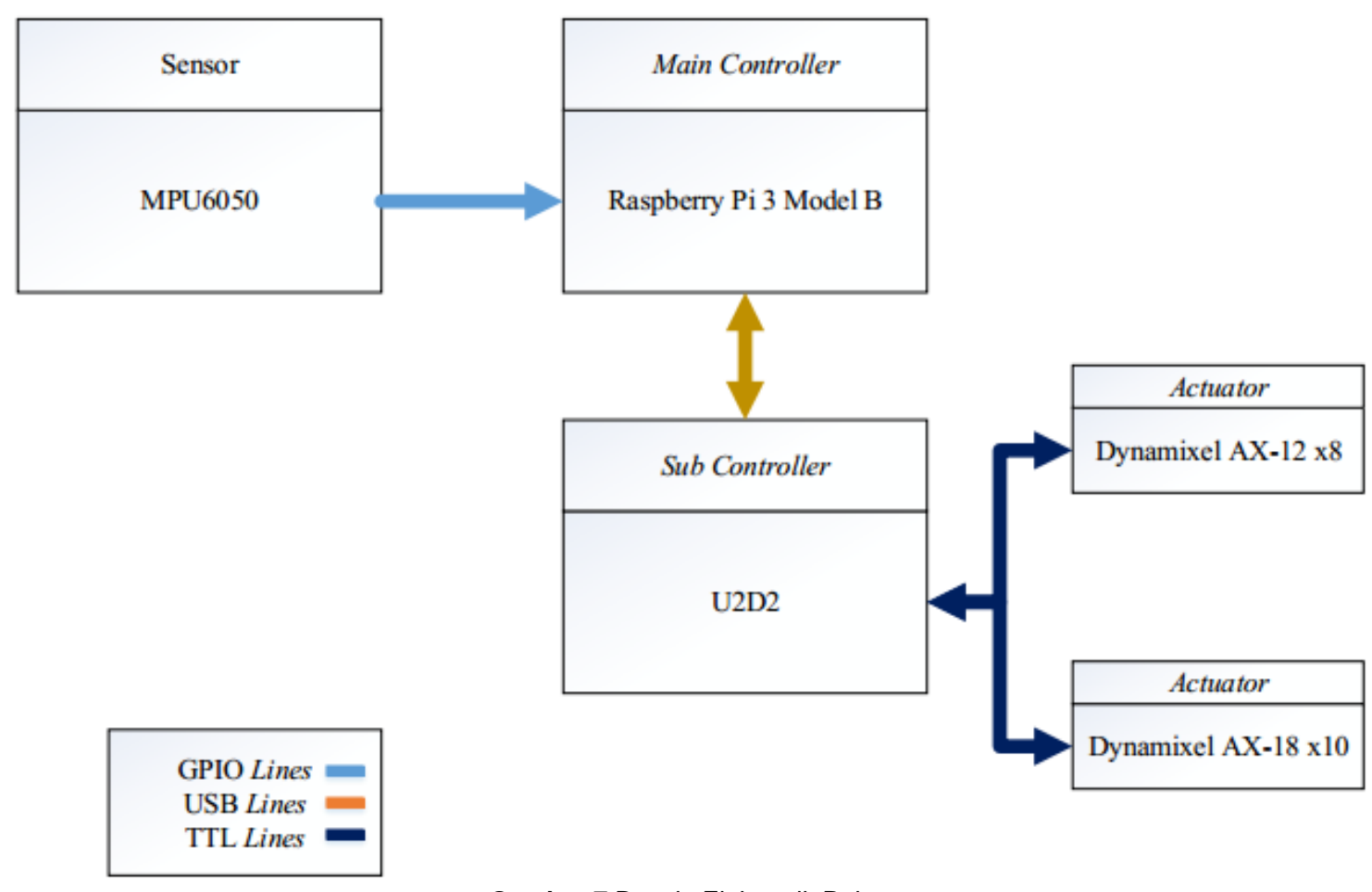

Gambar 7 Desain Elektronik Robot 


\subsection{Gerakan Statis}

Pada pergerakan robot, gerakan statis robot dibangkitkan dengan memperhatikan titik Center of Gravity (COG) dari robot humanoid dalam menentukan pose gerakan robot. Alur pembuatan gerakan statis adalah sebagai berikut.

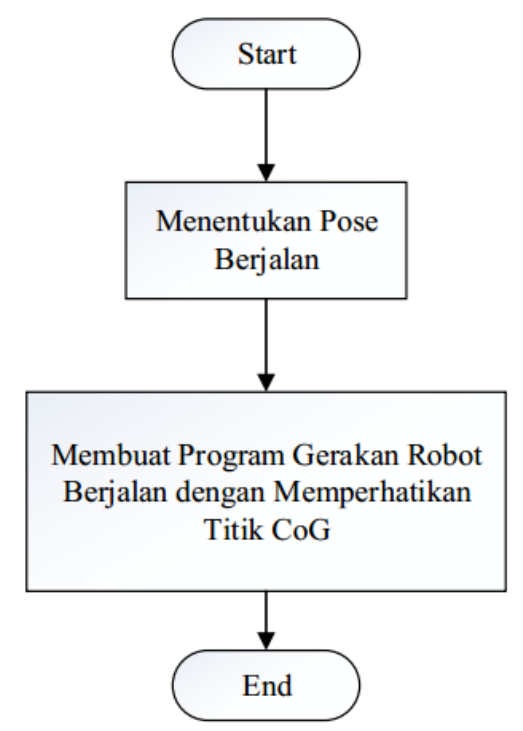

Gambar 8 Flowchart Gerakan Statis

Pada gerakan statis hal yang paling awal dilakukan adalah menentukan pose berjalan. Dalam menentukan pose berjalan perlu diperhatikan titik COG dari robot agar tetap tegak lurus dengan area pijakan. Setelah mendapatkan pose berjalan, selanjutnya menentukan sudut setiap DOF (Degree of Freedom) agar pose robot saat berjalan sesuai dengan yang diinginkan.

\section{HASIL DAN PEMBAHASAN}

\subsection{Hasil}

\subsubsection{Realisasi Hardware}

Pada penelitian ini robot yang digunakan adalah robot humanoid bioloid GP yang telah dimodifikasi sedemikian rupa agar robot dapat memenuhi kriteria sebagai robot sepakbola. Adapun perubahan yang dilakukan adalah menambah 2 sevo dynamixel AX-12 pada bagian kepala robot, penambahan kamera pada robot, penambahan mini $P C$ dengan Raspberry $P \mathrm{i}$ Model 3B yang dipasang pada bagian depan tubuh robot, dan penambahan sensor IMU gyroscope dan accelerometer yang dipasang pada titik COG robot humanoid.

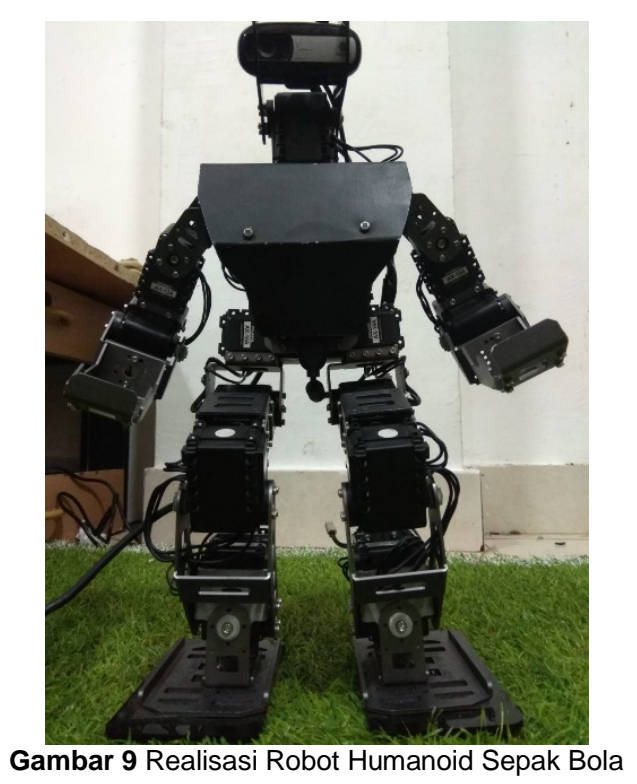

Gambar 9 merupakan tampilan robot yang telah dimodifikasi. Pada bagian depan tubuh robot diberikan seng baja yang telah dibentuk sedemikian rupa agar dapat melindungi Raspberry $\mathrm{Pi}$ yang diletakkan pada bagian depan tubuh robot.

\begin{tabular}{|c|c|c|}
\multicolumn{3}{c}{ Tabel 2 Spesifikasi Robot Humanoid } \\
\hline No & Spesifikasi & Keterangan \\
\hline 1 & Tinggi Robot & $45 \mathrm{~cm}$ \\
\hline 2 & Lebar Robot & $48 \mathrm{~cm}$ \\
\hline 3 & $\begin{array}{c}\text { Degree of } \\
\text { Freedom }\end{array}$ & 18 \\
\hline 4 & Aktuator & $\begin{array}{c}\text { Dynamixel } \\
\text { AX-12 } \\
\text { Dynamixel } \\
\text { AX-18 }\end{array}$ \\
\hline 5 & Supply Daya & $\begin{array}{c}\text { Baterai Lipo } \\
12 \text { V } 1000 \\
\text { mAh }\end{array}$ \\
\hline 6 & Controller & Raspberry Pi 3 \\
\hline 7 & Kamera & $\begin{array}{c}\text { Logitech } \\
\text { Webcam } \\
\text { C170 }\end{array}$ \\
\hline 8 & Sub-Controller & CM-530 \\
\hline
\end{tabular}




\subsubsection{Bagian Kepala Robot}

Pada bagian kepala robot terdiri atas 2 servo dynamixel AX-12 yang dipasang sedemikian rupa sehingga robot dapat menggerakkan kepala ke atas dan bawah serta ke samping kanan dan kiri. Kamera dipasang dengan frame akrilik sehingga kamera dapat bergerak sesuai dengan arah gerakan kedua servo tersebut

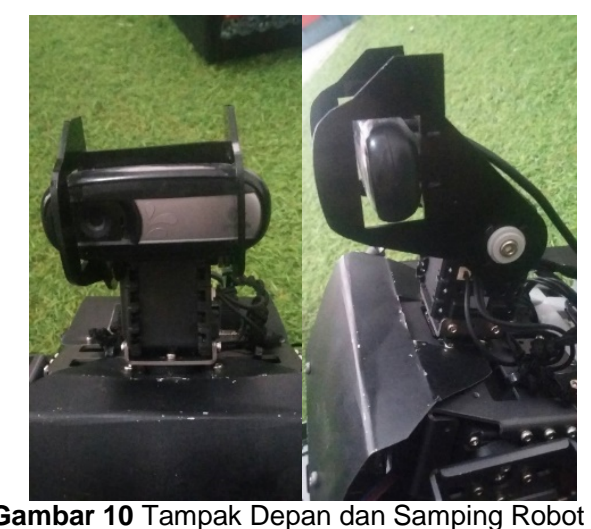

\subsubsection{Bagian Tubuh Robot}

Pada bagian depan tubuh robot dipasang main controller yaitu Raspberry Pi 3 Model B yang bertugas mengolah data kamera agar dapat mendeteksi bola maupun gawang. Pada bagian belakang tubuh robot dipasang sub controller yaitu U2D2 yang bertugas menggerakkan aktuator dan juga dipasang baterai Lipo $1000 \mathrm{mAh}$ dan bertegangan $12 \mathrm{~V}$ sebagai supply daya. Tegangan kerja yang digunakan oleh Raspberry Pi 3 Model B adalah $5 \mathrm{~V}$ sehingga tegangan baterai perlu diturunkan menggunakan modul step down. Bagian depan dan belakang tubuh robot ditutup menggunakan baja ringan agar dapat melindungi rangkaian saat robot terjatuh. Pada bagian belakang tubuh robot juga dipasang 2 saklar yang berfungsi untuk mengaktifkan atau menon-aktifkan maincontroller dan sub-controller.

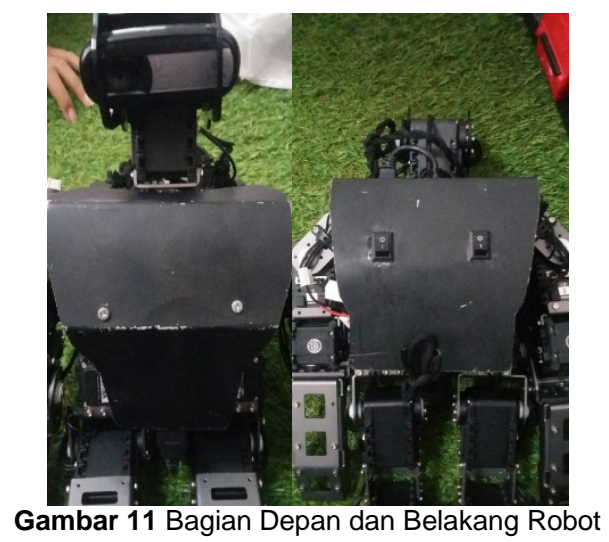

\subsubsection{Bagian Lengan Robot}

Pada bagian lengan robot dipasang 3 aktuator yang terdiri atas servo dynamixel AX-12 yang dipasang dengan frame aluminium. Lengan robot dirangkai sedemikian rupa agar lengan digerakkan ke depan dan ke belakang serta ke kanan dan ke kiri.

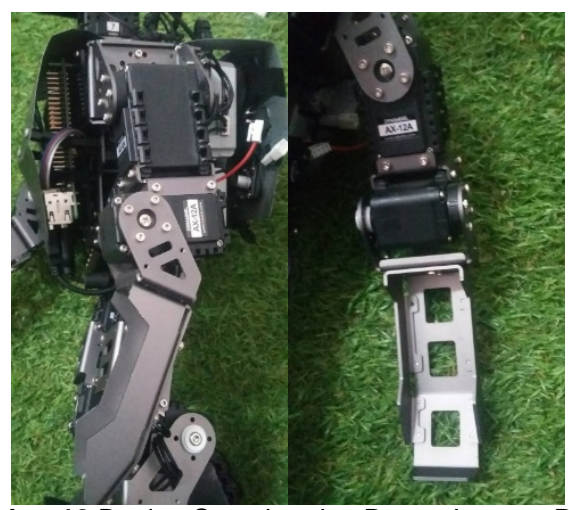

Gambar 12 Bagian Samping dan Depan Lengan Robot

\subsubsection{Bagian Kaki Robot}

Pada bagian kaki robot terdiri atas 10 aktuator yang menggunakan servo dynamixel AX-18 dan dirangkai dengan frame aluminium. Pada bagian kaki dibentuk sedemikian rupa sehingga dapat digerakkan maju, belakang, kiri, dan kanan. 


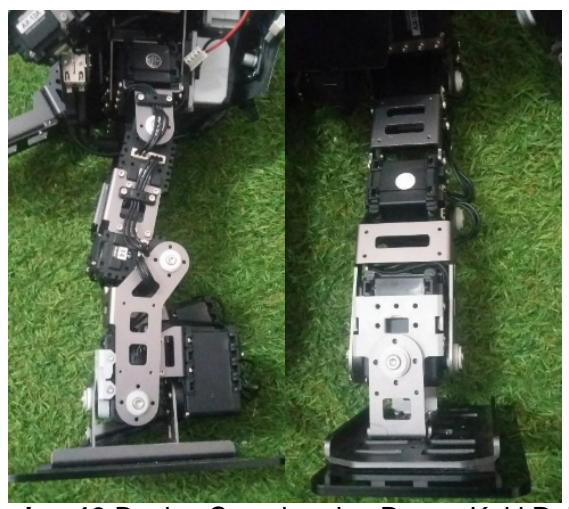

Gambar 13 Bagian Samping dan Depan Kaki Robot

\subsection{Pembahasan}

\subsubsection{Pengujian Sensor MPU6050}

Pengujian ini dilakukan dengan penggunaan pose robot stand by yakni robot berdiri dengan dengan kaki yang sedikit ditekuk. Pengujian dilakukan sebanyak 5 kali yakni robot posisi stand by, dimiringkan ke depan, ke belakang, ke kiri, dan ke kanan. Data-data yang diperoleh ditunjukan pada gambar $14-18$.

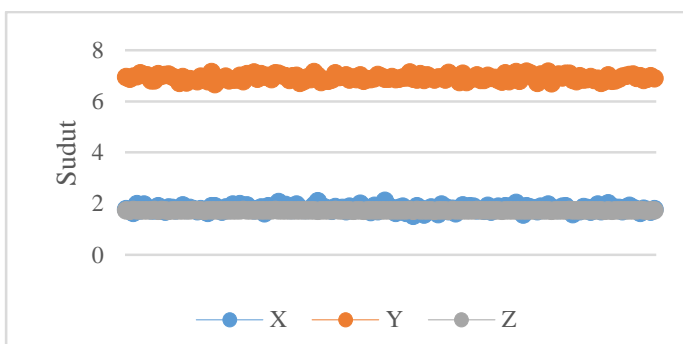

Gambar 14 Grafik Data Sensor MPU6050 Posisi Stand By

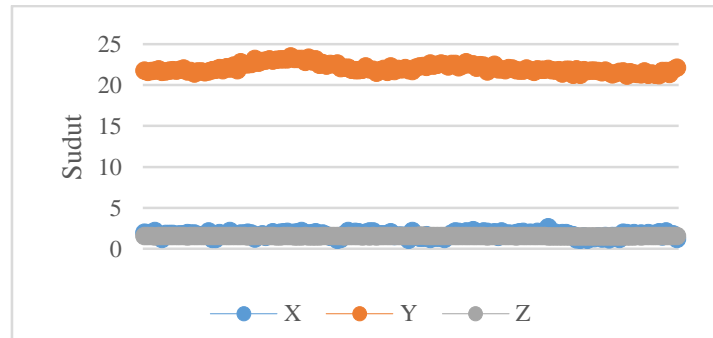

Gambar 15 Grafik Data Sensor MPU6050 Posisi Stand By Dimiringkan ke Depan

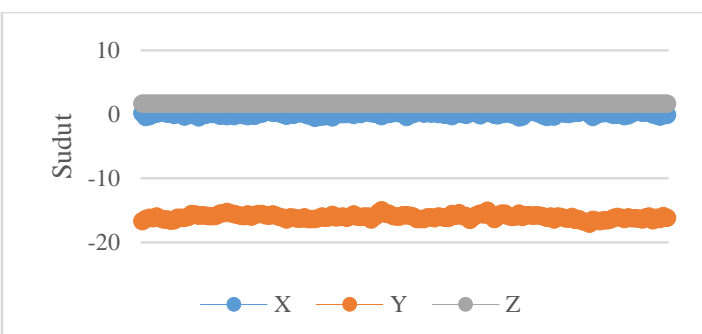

Gambar 16 Grafik Data Sensor MPU6050 Posisi Stand By Dimiringkan ke Belakang

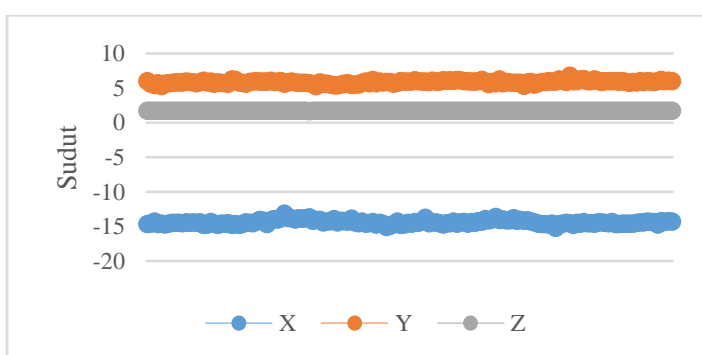

Gambar 17 Grafik Data Sensor MPU6050 Posisi Stand By Dimiringkan ke Kanan

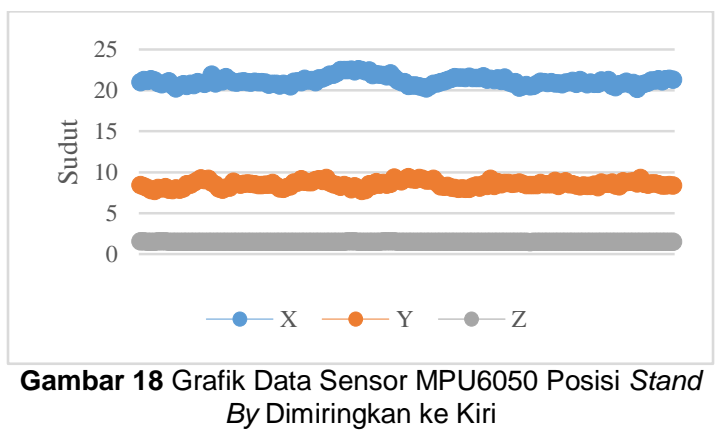

\subsubsection{Pengujian Gerakan Statis}

Pengujian pada gerakan statis dilakukan dengan mengeksekusi program robot berjalan. Robot akan dijalankan sejauh $100 \mathrm{~cm}$ pada 2 lintasan berbeda yakni karpet rumput sintetis dengan tinggi rumput $1 \mathrm{~cm}$ dan lantai keramik. Kemudian diamati output dari sensor MPU6050 dan juga diamati apakah robot terjatuh atau tidak. 


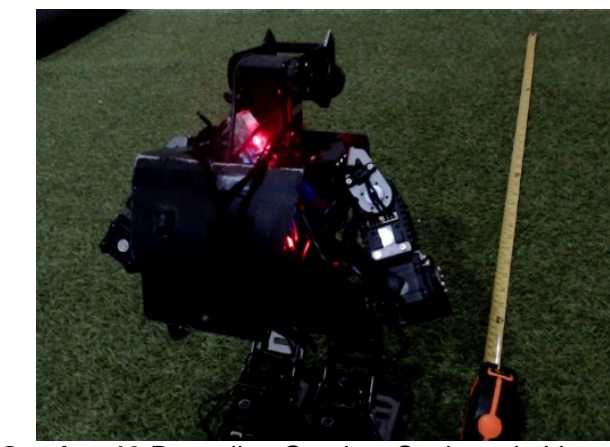

Gambar 19 Pengujian Gerakan Statis pada Lintasan Berumput

Pengujian dilakukan dengan robot berjalan sejauh $100 \mathrm{~cm}$ pada lintasan berumput kemudian dari salah satu pengujian didapat output dari sensor MPU6050 seperti pada gambar 20 berikut.

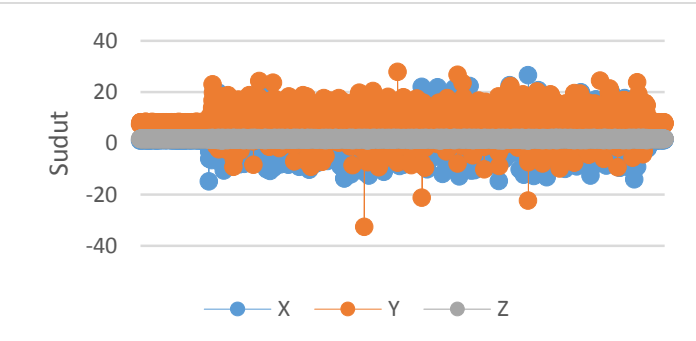

Gambar 20 Grafik Output Sensor MPU6050 pada Pengujian 1 Gerakan Statis pada Lintasan Berumput

Pengujian dilakukan dengan 10 kali pengujian pada lintasan berumput dan hasil dari pengujian tersebut dijabarkan pada tabel 3.

Tabel 3 Hasil Pengujian Gerakan Statis pada Lintasan Berumput

\begin{tabular}{|c|l|}
\hline Pengujian & \multicolumn{1}{|c|}{ Keadaan Robot } \\
\hline 1 & Tidak Terjatuh sampai Finish \\
\hline 2 & Tidak Terjatuh sampai Finish \\
\hline 3 & Tidak Terjatuh sampai Finish \\
\hline 4 & Tidak Terjatuh sampai Finish \\
\hline 5 & Tidak Terjatuh sampai Finish \\
\hline 6 & Tidak Terjatuh sampai Finish \\
\hline 7 & Tidak Terjatuh sampai Finish \\
\hline 8 & Tidak Terjatuh sampai Finish \\
\hline 9 & Tidak Terjatuh sampai Finish \\
\hline 10 & Tidak Terjatuh sampai Finish \\
\hline
\end{tabular}

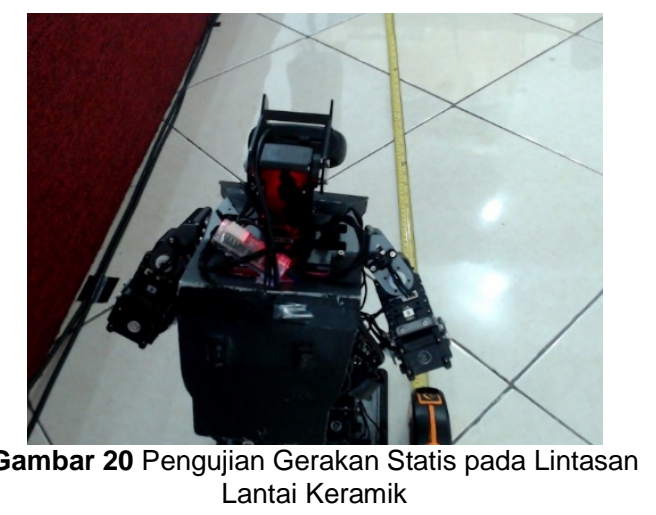

Pengujian selanjutnya dilakukan pada lintasan lantai keramik dengan robot berjalan selama $100 \mathrm{~cm}$. Dari salah satu pengujian yang telah dilakukan didapatkan output dari sensor MPU6050 yang ditujukan pada gambar 21 .

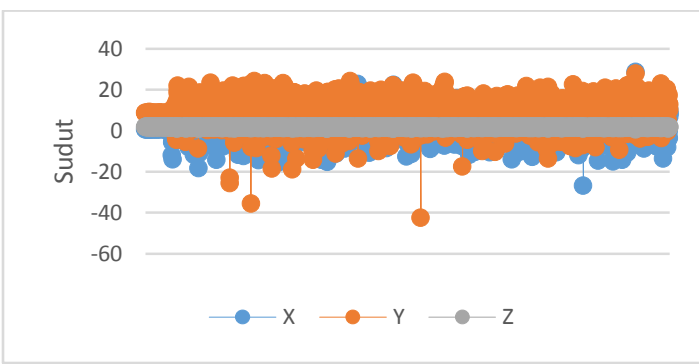

Gambar 21 Grafik Output Sensor MPU6050 pada Pengujian 1 Gerakan Statis pada Lintasan Lantai Berkeramik

Pengujian dilakukan dengan 10 kali pengujian pada lintasan lantai berkeramik dan hasil dari pengujian tersebut dijabarkan pada tabel 4.

Tabel 4 Hasil Pengujian Gerakan Statis pada Lintasan Berkeramik

\begin{tabular}{|c|l|}
\hline Pengujian & \multicolumn{1}{|c|}{ Keadaan Robot } \\
\hline 1 & Tidak Terjatuh sampai Finish \\
\hline 2 & Tidak Terjatuh sampai Finish \\
\hline 3 & Tidak Terjatuh sampai Finish \\
\hline 4 & Tidak Terjatuh sampai Finish \\
\hline 5 & Tidak Terjatuh sampai Finish \\
\hline 6 & Tidak Terjatuh sampai Finish \\
\hline 7 & Tidak Terjatuh sampai Finish \\
\hline 8 & Tidak Terjatuh sampai Finish \\
\hline 9 & Tidak Terjatuh sampai Finish \\
\hline 10 & Tidak Terjatuh sampai Finish \\
\hline
\end{tabular}




\subsubsection{Analisa Hasil Data Pengujian Sensor MPU6050}

Data yang telah didapat dari pengujian posisi robot dalam keadaan stand by berdasarkan gambar grafik 14 menunjukan bahwa keadaan robot stabil saat diam pada sumbu $Y$ data berkisar antara $6^{\circ}$ $8^{\circ}$, pada sumbu $X$ berkisar antara $1^{\circ}-2^{\circ}$, dan pada sumbu $Z$ berkisar antara $1^{\circ}-2^{\circ}$. Pengujian selanjutnya dilakukan dengan memiringkan robot ke depan pada saat robot dalam posisi stand by menunjukan perubahan data yang lebih besar pada sumbu $Y$ seperti pada gambar grafik 15. Pengujian selanjutnya dilakukan dengan memiringkan robot ke belakang pada saat robot dalam posisi stand by menunjukan perubahan data yang lebih kecil pada sumbu Y seperti pada gambar grafik 16 . Pengujian selanjutnya dilakukan dengan memiringkan robot ke kanan pada saat robot dalam posisi stand by menunjukan perubahan data yang lebih kecil pada sumbu $X$ seperti pada gambar grafik 17 . Pengujian selanjutnya dilakukan dengan memiringkan robot ke kiri pada saat robot dalam posisi stand by menunjukan perubahan data yang lebih besar pada sumbu $X$ seperti pada gambar grafik 18.

Tabel 5 Analisa Data Hasil Pengujian Sensor MPU6050

\begin{tabular}{|c|c|c|c|}
\hline Posisi Robot & Sumbu X & Sumbu Y & Sumbu Z \\
\hline Berdiri & $1^{\circ}-2^{\circ}$ & $6^{\circ}-8^{\circ}$ & $1^{\circ}-2^{\circ}$ \\
\hline $\begin{array}{c}\text { Berdiri } \\
\text { Dimiringkan } \\
\text { Ke Depan }\end{array}$ & $1^{\circ}-2^{\circ}$ & $20^{\circ}-22^{\circ}$ & $1^{\circ}-2^{\circ}$ \\
\hline $\begin{array}{c}\text { Berdiri } \\
\text { pimiringkan ke } \\
\text { Belakang }\end{array}$ & $1^{\circ}-2^{\circ}$ & $-15^{\circ}--18$ & $1^{\circ}-2^{\circ}$ \\
\hline $\begin{array}{c}\text { Berdiri } \\
\text { pimiringkan ke } \\
\text { Kanan }\end{array}$ & $-15^{\circ}--16^{\circ}$ & $5^{\circ}-6^{\circ}$ & $1^{\circ}-2^{\circ}$ \\
\hline $\begin{array}{c}\text { Berdiri } \\
\text { pimiringkan ke } \\
\text { Kiri }\end{array}$ & $20^{\circ}-23^{\circ}$ & $6^{\circ}-8^{\circ}$ & $1^{\circ}-2^{\circ}$ \\
\hline
\end{tabular}

\subsubsection{Analisa Hasil Data Pengujian Gerakan Statis pada Lintasan Berumput}

Analisa dilakukan dengan mencari data maksimum, minimum, rata-rata, dan standar deviasi dari data yang telah didapatkan seperti yang ditujukan pada tabel berikut.

Tabel 6 Analisa Data Hasil Pengujian Gerakan Statis pada Lintasan Berumput

\begin{tabular}{|c|c|c|c|}
\hline Data & $\mathrm{X}$ & $\mathrm{Y}$ & $\mathrm{Z}$ \\
\hline Maksimum & 26,54 & 27,81 & 1,99 \\
\hline Minimum & $-14,86$ & $-32,65$ & 0,97 \\
\hline Rata-Rata & 2,10 & 7,97 & 1,71 \\
\hline $\begin{array}{c}\text { Standar } \\
\text { Deviasi }\end{array}$ & 4,49 & 4,18 & 0,12 \\
\hline
\end{tabular}

Berdasarkan hasil pengujian serta data dari sensor MPU6050 diketahui bahwa robot selama berjalan tidak terjatuh. Hal ini disebabkan karena setiap pose dari pembuatan gerakan jalan pada robot menerapkan konsep titik COG. Namun, berdasarkan hasil dari data sensor MPU6050 terdapat perubahan kemiringan pada robot. Hal ini, disebabkan karena faktor eksternal dari robot yakni pada lingkungan robot saat berjalan.

\subsubsection{Analisa Hasil Data Pengujian Gerakan Statis pada Lintasan} Lantai Berkeramik

Analisa dilakukan dengan mencari data maksimum, minimum, rata-rata, dan standar deviasi dari data yang telah didapatkan seperti yang ditujukan pada tabel 7.

Tabel 7 Analisa Data Hasil Pengujian Gerakan Statis pada Lintasan Lantai Berkeramik

\begin{tabular}{|c|c|c|c|}
\hline Data & X & Y & Z \\
\hline Maksimum & 28,74 & 27,82 & 1,99 \\
\hline Minimum & $-26,93$ & $-42,41$ & 0,56 \\
\hline Rata-Rata & 2,05 & 8,82 & 1,69 \\
\hline $\begin{array}{c}\text { Standar } \\
\text { Deviasi }\end{array}$ & 4,78 & 5,49 & 0,15 \\
\hline
\end{tabular}

Berdasarkan hasil pengujian serta data dari sensor MPU6050 diketahui bahwa robot selama berjalan tidak terjatuh. Hal ini disebabkan karena setiap pose dari pembuatan gerakan jalan pada robot menerapkan konsep titik COG. Namun, berdasarkan hasil dari data sensor MPU6050 terdapat perubahan kemiringan pada robot. Hal ini, disebabkan karena faktor eksternal dari robot yakni pada lingkungan robot saat berjalan. 


\section{SIMPULAN DAN SARAN}

\subsection{Simpulan}

Berdasarkan teori-teori yang sudah ada serta hasil pengujian dan analisa dari pergerakan robot humanoid berjalan, dalam membuat pergerakan robot perlu diperhatikan titik dari COG (Center of Gravity) agar selalu berada dalam polygon support dari robot agar robot tidak mudah terjatuh saat berjalan.

Sensor MPU6050 dapat digunakan sebagai pendeteksi kemiringan dari titik COG (Center of Gravity) robot humanoid. Data yang didapat dari sensor MPU6050 adalah data roll, pitch, dan yaw yang merupakan data dari kemiringan robot. Data kemiringan robot yang paling mengalami perubahan selama robot berjalan adalah roll dan pitch atau pada sumbu $\mathrm{X}$ dan $\mathrm{Y}$. Data sensor MPU6050 pada saat robot dimiringkan ke depan dan ke belakang hanya mengalami perubahan pada sumbu Y. Sedangkan data sensor MPU6050 pada saat robot dimiringkan ke kanan dan ke kiri hanya mengalami perubahan pada sumbu $X$.

Pengujian gerakan statis pada lintasan berumput memiliki rata-rata nilai yang lebih besar pada sumbu $X$ dan $Y$ ketimbang pada lintasan lantai berkeramik. Hal ini disebabkan oleh faktor lingkungan pada lantai keramik yang memiliki tingkat gaya gesek yang lebih kecil dibandingkan dengan lintasan berumput yang membuat robot mengalami slip pada saat bergerak.

\subsection{Saran}

Pergerakan statis robot masih terdapat gangguan kestabilan pada kemiringan titik COG. Hal ini dapat diatasi dengan menerapkan pergerakan dinamis robot yang mana robot dapat menstabilkan pose agar kemiringan titik COG tidak mengalami perubahan yang drastis.

\section{DAFTAR PUSTAKA}

[1] M. Sholihah, W. Adiprawita and K. Mutijarsa, "Design and Implementation of Playing Soccer Communication System and Strategy Algorithm on Humanoid Robot Soccer KidSize," 2014 IEEE 4th
International Conference on System Engineering and Technology (ICSET), 2014.

[2] Kemenristekdikti, "Panduan Kontes Robot Sepak Bola Indonesia Divisi Humanoid," 2017.

[3] D. Caysar, "Pengaturan Pergerakan Robot Lengan Smart Arm Robotic Ax-12a Melalui Pendekatan Geometyr Based Kinematic Menggunakan Arduino," SKRIPSI, pp. 1-8, 2014.

[4] A. A. Saputra, A. Al-Farouq, H. A. AlKhusna, E. A. Herbanu, H. Bastian and D. Pritovani, "Implementasi Pembangkitan Pola Gerakan Berjalan Berbasis Trajektori Joint Pada Robot EROS-1(EEPIS Robosoccer-1)," ISRC, pp. 45-48, 2013. 